\title{
Millennium Development Goals: All good things must come to an end, so what next?
}

In 2000 all 152 member states of the United Nations adopted the Millennium Declaration. The declaration detailed a roadmap to be followed from 2000-2015, leading to eight Millennium Development Goals (MDGs) that have subsequently guided global development actions (Table 1).

\section{Table 1 Eight Millennium Development Goals (MDGs)}

1. Eradicate Extreme Poverty \& Hunger

2. Achieve Universal Primary Education

3. Promote Gender Equality \& Empower Women

4. Reduce Child Mortality

5. Improve Maternal Health

6. Combat HIV/AIDS, Malaria \& Other Diseases

7. Ensure Environmental Sustainability

8. Develop a Global Partnership for Development

The 2015 target date for the MDGs is now in sight. Whether countries achieve some or all of the eight MDGs, surpass them or achieve none, the MDGs are a strong catalyst for focusing the political agenda and having a profound effect on governments, donors, and international organisations.

MDGs 4 and 5 have been a great success in focusing attention on reproductive health and rights and some countries have made substantial progress. Last autumn Midwifery dedicated a Special Issue to the MDGs (Lockley 2013), covering countries such as Afghanistan (Mansoor et al. 2013; Turkmani et al. 2013), Mexico (Walker et al. 2013), Nepal (Bogren et al. 2013), Sierra Leone (Ngongo et al. 2013) and the Yemen (Kempe et al. 2013). The evidence across these and other papers is convincing. Even in countries that have not yet achieved the goals the very existence of targets, e.g. reduce by three-quarters, between 1990 and 2015, the maternal mortality ratio (MMR) has helped to improve women's health and survival, as well as that of newborns. Furthermore, tracking the proportion of births attended by skilled health workers as part of MDG 5 has focused attention on the need for improvements in professional care at birth.

\section{The way forward}


The international health and development communities are now looking to the next generation of global health priorities and targets for 2030/2035. The UN consultation on the 'World We Want' has included the Thematic Consultation and the High Level Dialogue on Health in the post-2015 development agenda (Task Team 2013). The aspiration of Universal Health Coverage (UHC) has gained significant international support. Its underpinning principle is rooted in theories of social justice and (gender) equity, and international covenants on the right to life to ensure that all people have access to quality health services.

However UHC cannot be achieved without a strong focus on Human Resources for Health, including the education, management, regulation and remuneration of a skilled health workforce (Campbell et al. forthcoming). We must remember that the midwifery workforce forms the backbone of universal access to reproductive health services. Being more aligned to a social model of childbirth than a medical model (van Teijlingen 2005), midwifery, with its emphasis on physiology, support for women and their newborns and low-tech approaches, may help to reduce medicalisation and intervention rates in the urban middle-classes in Low and Middle-Income Countries (LMICs), where too often private care providers and hospitals have 'perverse' incentives to increase the caesarean section rate.

On February $5^{\text {th }} 2014$ we have planned a global agenda influencing conference at Bournemouth University. The multidisciplinary meeting will bring together viewpoints from clinicians, academics and other stakeholders to understand the global challenges in the next fifteen years and the place that midwifery can occupy in the range of solutions.

The conference will take into account midwifery professionals' viewpoints, research on midwifery, social science and demography within the broader aspirations for UHC of socioculturally acceptable (appropriate) care. The dynamics of population growth and increasing birth rates cut across the dimensions of social, economic and environmental development, requiring a human rights-based policy response, respectful of the rights and needs of women. The World Bank (2013) suggests that 96\% of the additional 1.4 billion people in LMICs in 2030 will live in cities. Urbanisation is likely to lead to greater marginalisation of those in remote and rural areas. It will also have a profound impact on health labour markets, with competing demands on the provision of urban/rural services and the need to ensure universal 
access. There is likely to be greater centralisation of overstressed urban services, that will squeeze rural health and maternity services, leaving the rural poor behind.

Core questions will be posed to participants ahead of the conference and discussed in depth. What type of midwifery services are required to support the changes ahead? What are the equality and equity implications of trends in access to and utilisation of maternal health services? Does the prescription for a 'skilled attendant' at every birth require new thinking? (Channon et al. 2012). Core to the conference is making this a global agenda. One disadvantage of the MDGs has been that they are regarded solely as LMIC's concern. While the spotlight has been elsewhere, there are some high-income countries that have witnessed increasing maternal mortality ratios. As we move towards the post-2015 declaration it's time to hold every country accountable for the health of their women and newborns.

Edwin van Teijlingen, MA, MEd, PhD (Professor) ${ }^{1}$

Vanora Hundley, BN, RM, MSc, PhD (Professor) ${ }^{1}$

Zoe Matthews, MSc, PhD (Professor) ${ }^{2}$

Gwyneth Lewis, OBE, MBBS, DSc, MSc, FRCOG, FACOG, FFPH (Professor) ${ }^{3}$

Wendy J. Graham, DPhil (Oxon) (Professor) ${ }^{4}$

James Campbell, MPH, MSc (Director) ${ }^{5}$

Petra ten Hoope-Bender, RM, MBA (Director RMNCH) ${ }^{5}$

Zoe A. Sheppard, BSc, PhD, (Research Fellow in Research Methods) ${ }^{1}$

Louise Hulton, MSc, PhD (Director)

\section{Affiliations}

1. CMMPH, Bournemouth University, UK

2. Centre for Global Health Population Poverty \& Policy, University of Southampton, UK

3. University College London, UK

4. Immpact, University of Aberdeen, UK.

5. ICS Integrare S.L., Spain.

6. Evidence for Action on Maternal \& Newborn Mortality, Options, London, UK 


\section{References}

Bogren, M.U., van Teijlingen, E., Berg, M., 2013. Where midwives are not yet recognised: A feasibility study of professional midwives in Nepal. Midwifery 29, 1103-1109.

Channon AA, Neal S, Matthews Z, Falkingham J. 2012. Maternal health inequalities over time: is there a common pathway? World We Want 2015 [online]. , 1-9. (online www.worldwewant2015.org/node/283339)

Campbell J, Buchan J, Cometto G, et al. (forthcoming) Human resources for health and universal health coverage: fostering equity and effective coverage. Bulletin of the World Health Organization

Kempe, A., Theorel, T., Noor-Aldin Alwazer F., et al. 2013. Yemeni women's perceptions of own authority during childbirth: What does it have to do with achieving the Millennium Development Goals? Midwifery 29, 1182--1189.

Lockley R., 2013. Editorial for Midwifery special issue on MDGs: Midwives and the Millennium Development Goals. Midwifery 29, 1073-1074.

Mansoor G.F., Hashemy, P., Gohar, F., et al., 2013. Midwifery retention and coverage and impact on service utilisation in Afghanistan. Midwifery 29, 1088-1094.

Ngongo, C., Christie, K., Holden, J 2013. Striving for excellence: Nurturing midwives' skills in Freetown, Sierra Leone. Midwifery 29, 1230-1234.

Task Team. 2013. Health in the Post-2015 Development Agenda: Report of the Global Thematic Consultation on Health (online: www.worldwewant2015.org/health ).

Turkmani, S., Currie, S., Mungia, J. et al., 2013. 'Midwives are the backbone of our health system': Lessons from Afghanistan to guide expansion of midwifery in challenging settings. Midwifery 29, 1166-1172.

van Teijlingen, E., 2005. A critical analysis of the medical model as used in the study of pregnancy and childbirth, Sociological Research Online, 10 (2) Web address: http://www.socresonline.org.uk/10/2/teijlingen.html

Walker, D., DeMaria, L., Gonzalez-Hernandez, D., et al., 2013. Are all skilled birth attendants created equal? A cluster randomised controlled study of non-physician based obstetric care in primary health care clinics in Mexico. Midwifery 29, 1199-1205.

World Bank, 2013. International Monetary Fund. Global Monitoring Report 2013. Rural-Urban Dynamics and the Millennium Development Goals. Washington DC: World Bank. 